\title{
Urban Environment Development based on Universal Design Principles
}

\author{
Bangun IR Harsritanto ${ }^{1, *}$ \\ ${ }^{1}$ Architecture Department of Engineering Faculty, Diponegoro University, Semarang - Indonesia
}

\begin{abstract}
Universal Design is a design which facilitated full range of human diversity. By applying Universal design principles, urban environment can be more functional and more user-friendly for everyone. This study examined five urban streets of South Korea as a country experienced on developing various urban street designs based on universal design. This study aimed to examine and compare the South Korea cases using seven principles of universal design. The research methods of this study are literature study, case study, and site observation. The results of this study are: South Korea cases are good practices, urgency of implementing the direction into local regulations; and change of urban development paradigm.
\end{abstract}

\section{Introduction}

Urban streetscape which designed and developed in detail with a special theme or purpose of urban development. However, not all people can access the specialized street easily because of their different ability (as the elderly, children and people with special needs).

Universal design (also called inclusive design or accessible design) refers to facility designs that accommodate the widest range of potential users, including people with mobility and visual disabilities and other special needs [11]. Universal design should be comprehensive from origin to destination for the greatest possible range of potential users. Universal design should consider all possible obstacles that may exist in buildings, transportation terminals, sidewalks, paths, roads and vehicles.

South Korea is one of the countries that applied universal design principles in public spaces and public buildings. South Korea applied it to ease the access for the elderly and disabled. The condition was happened because the number of this last category in South Korea is steadily increasing due to congenital disabilities, aging and the increase of physical impairments from accidents. This study examined five urban streets of South Korea as a country experienced on developing various urban street designs based on universal design.

\section{Method}

This study was performed with three research methods, such as:

1. Literatures study was compiled and analyzed several related literature to construct evaluation sheet of this study.

\footnotetext{
Corresponding author: bangunirh@arsitektur.undip.ac.id
}

2. Site observation was used to inspect South Korea urban streets with evaluation sheet which constructed before, and measured by interval scales of five points.

3. Case study was used to explain several phenomena happening on the site observation and later on can be generalized into the bigger scope of research area.

\section{Discussions}

\subsection{Literature summary}

Summarized from the 7 existing specialized street guidelines (see table 1), there were substantial issues that need to be fixed and completed by this dissertation study, such as:

1. the previous studies were purposed only for tourism street facilities [1];[2];[3] which resulted an artificial disneyfication a of specialized street without concerning on daily activities [4]. This artificial disneyfication of tourism oftenly force the natural expression of the urban society to develop their neighborhood.

2. the previous guidelines were oriented to design local district [5];[6] which resulted the unsustainable specialized street fabric from and to the site. This orientation of design built exclusive area on the city.

3 . the previous guidelines were a lack of universal design appliance especially: [7]; [8] which promote distinct disable people as a different kind of person.

\footnotetext{
${ }^{a}$ A process of how real world is becoming more like a theme park (eg: Disney world) ; standardisation; popular culture; superficial and globalization
} 
The facilities were designed specifically for them who concerned on the referenced literature [9].The designer should learn about the barriers, difficulties and especially the various needs of people and [10] reduce dependency to other people helps.

\subsection{Site observation scale and objects}

Present condition analysis by universal design principles which derived from literature study and resumed as an evaluation sheet to compare with cases study and the site survey result. The numerical results were generated from the interval scale criteria which consist of 5 scales valued from the worst is 1 and the best is 5 .

From three major cities, five famous specialized streets were chosen to be studied on this dissertation :

1. Insadong and Gwanghwamun area in Seoul (the biggest city in South Korea)

2. Nampodong and Seomyeon area in Busan (second biggest city)

3. Yangyeonsi, Banwoldang in Daegu (third biggest city
The observation objects were [12] :

1. Parking lots

2. Bus stop/subway gates

3. Linkage design

4. Street furnitures

5. Street utilities

6. Signages

7. Street materials

8. Pedestrian spaces

\section{Results}

The statistical result showed that there are two dominant streets to be good examples which are Gwanghwamun and Insadong (see figure 1). The Banwoldang Yangnyeonsi at Daegu has the worst result on 6 sections with scores 3.19 on bus stop/subway, 2.77 on street furniture, 2.79 on street utilities, 2.79 on signages, 2.57 on pedestrian space, and 3.08 on linkage design. The 2nd worst result is Seomyeon which score 3.13 in parking lot section and 3.11 in street material

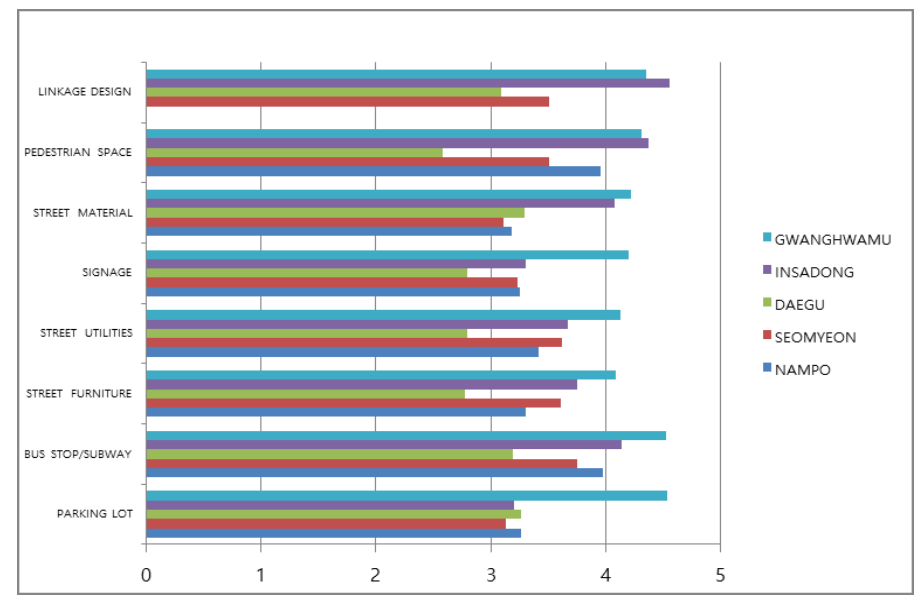

Fig. 1. South Korea's Urban Street Section's Statistical Analysis

In highlight score of universal design application, Gwanghwamun got all highest score, then followed by Insadong, Nampo and Seomyeon. In the opposite Daegu, Yangnyeonsi street got all lowest score in universal design applications. More detail on the findings will be explained in next sub-chapter along with the universal design related value.

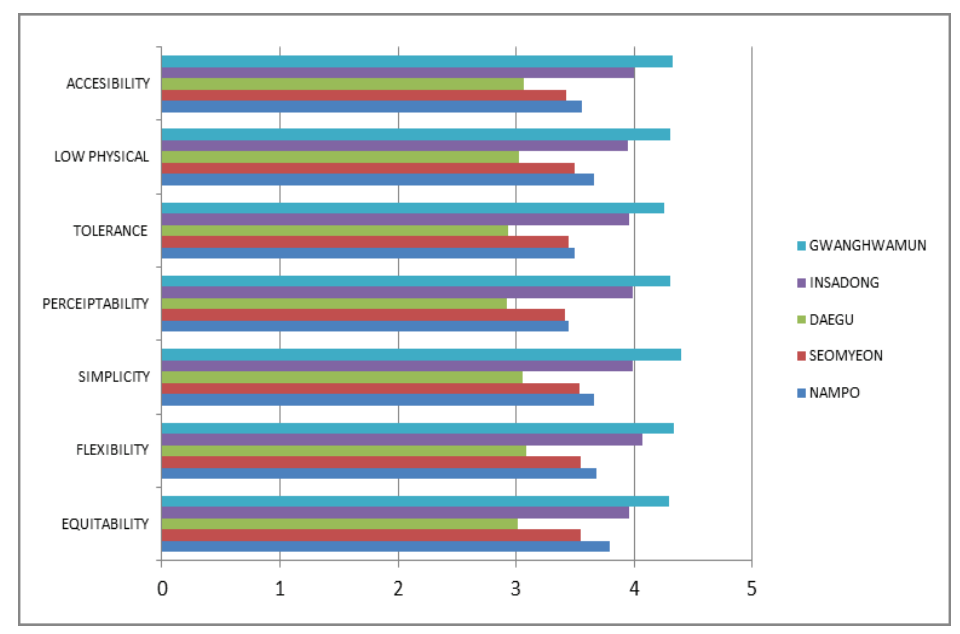

Fig. 2. Universal Design Application Statistical Anays is of South Korea's Specialized Streets 


\begin{tabular}{|c|c|c|c|c|c|c|c|}
\hline 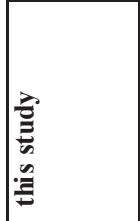 & 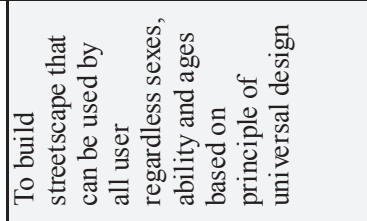 & 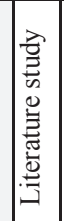 & 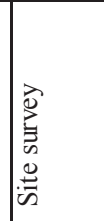 & 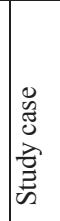 & 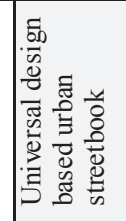 & 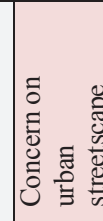 & 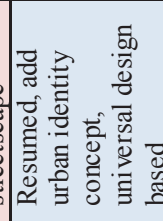 \\
\hline 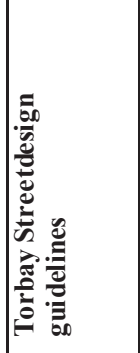 & 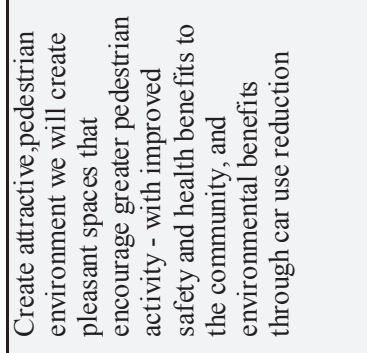 & 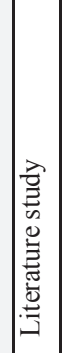 & 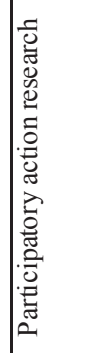 & & 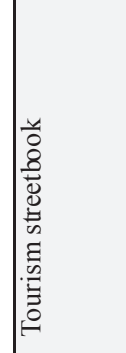 & 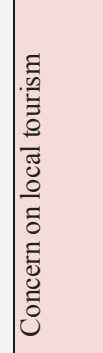 & 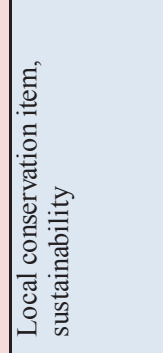 \\
\hline 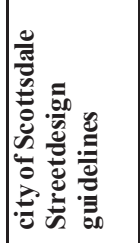 & 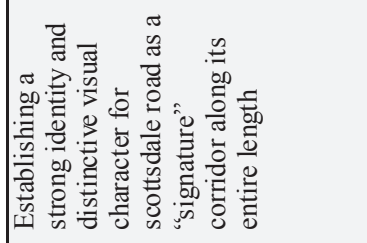 & 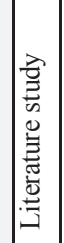 & 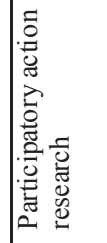 & & 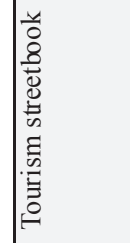 & 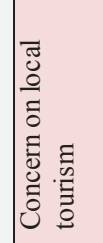 & 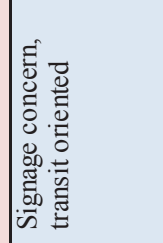 \\
\hline 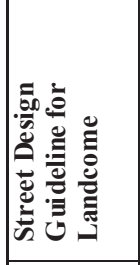 & 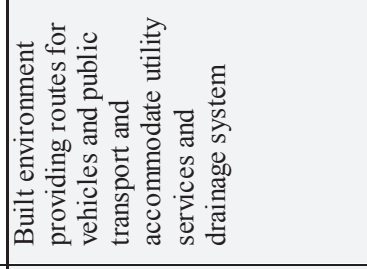 & 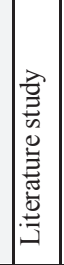 & 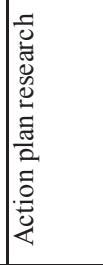 & & 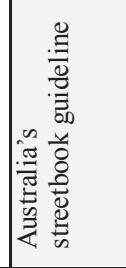 & 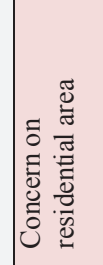 & 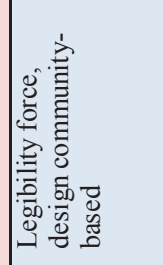 \\
\hline 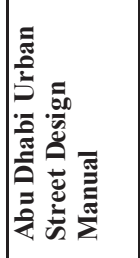 & 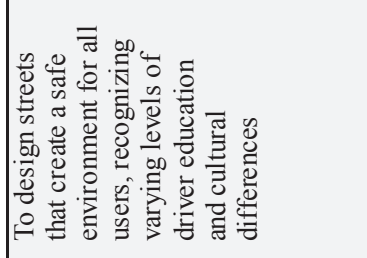 & 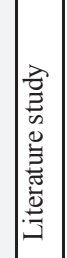 & 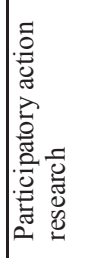 & & 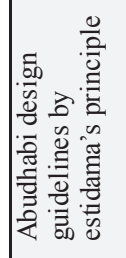 & 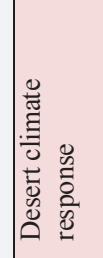 & 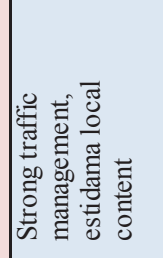 \\
\hline 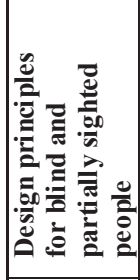 & 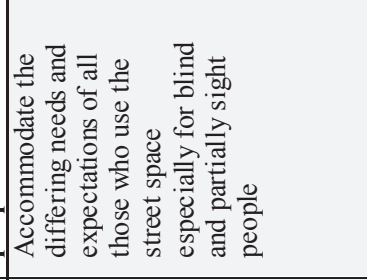 & 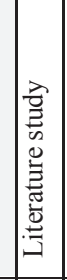 & 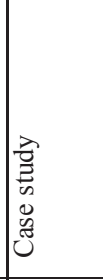 & 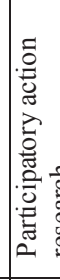 & 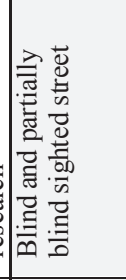 & 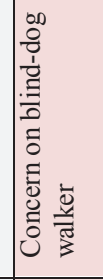 & 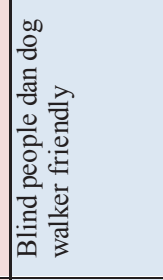 \\
\hline 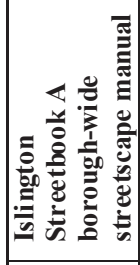 & 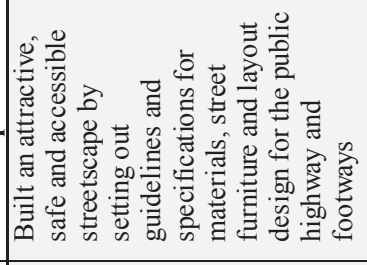 & 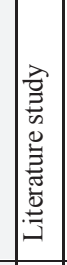 & 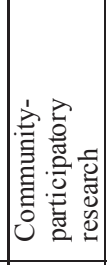 & & 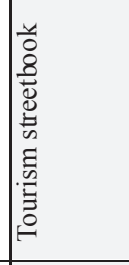 & 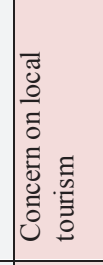 & 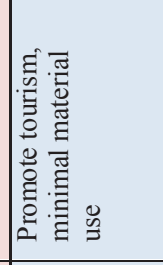 \\
\hline 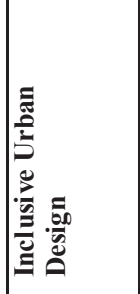 & 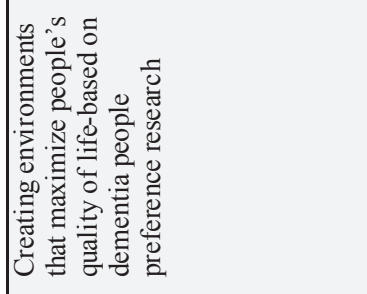 & 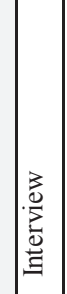 & $\mid$ & 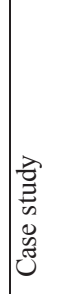 & 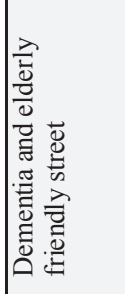 & 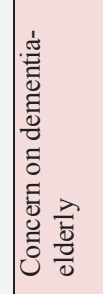 & 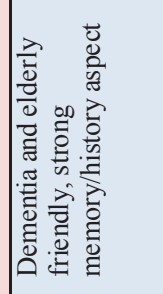 \\
\hline Е & 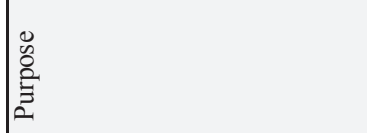 & 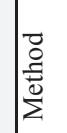 & & & 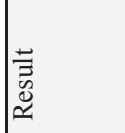 & $\tilde{\tilde{o}}$ & 总 \\
\hline$\cong$ & & - & & $n$ & & & \\
\hline
\end{tabular}


According to the evaluation, the first major problems in the accessibilities were the facilities of the parking lot and street utilities. Even though the location of parking lots was near (less than $200 \mathrm{~m}$ from the specialized street), the amenities for disabled persons in special parking lots and the signage were not well supported. In Nampodong area, the parking lots were located on several buildings in a small alley that provided difficulties for car on wayfinding and access. More added problems were the locator signs which were in the Korean alphabet without guidance any picture for people who didn't study Korean. In other facts at Insadong, the location of parking lots was more accessible horizontally but some raised levels and small bombs burden the wheelchair accessibility. Most of the signage attached is bilingual, which helps international people to notice it. Since the designed parking spaces should be provided for all, normal and disabled passengers, every passenger shall be able to open the door fully to get in or out the vehicles and manoeuvre from the street to the lots in a low physical effort. The locations of parking lots on the main street with a minimum width of $3 \mathrm{~m}$ for single car manoeuvres. The parking lot also must be equipped with firm, suitable ramps, slip resistant and tactile pavements for the special needs lots. In addition, the locator signages shall be written in international languages and better to put a braille sign at the decision point.

The second point that can be marked is the bus stop and subway facilities. According to the evaluation, the first point of local character that give notice to the passengers about the specialized street was unnoticeable. The implication of uniformity on subway exits and bus stop was also provided by the visual surrounding adaptation to give assistance to the passenger. The effect of unnoticeable spot also may attract blockade and visual barrier which made difficulties to wayfinding in this area. The accessibility and low effort of elevators and escalators facility were not installed properly, especially on Insadong but these items were provided on Nampodong gate of Gwangbok street which can indicate that instalment of subway station related to specialized street design. Those situations also appear on bus stop instalment in both specialized streets. The bus stops of Insadongs were located disparsely on around the areas. At Nampodong, the facilities were located on start, end, and priority points, but both areas were covered $500 \mathrm{~m}$ radius of bus stops and subway exits. In the specific enclosure of the point, the Insadong bus stop was not equipped with good enclosure and in the oversized. On three spots of Nampo bus shelters were erected in 2,1m height roof linked with several special design bus for a wheelchair. The signage of this spot was installed with international signs, symbols and words, even though they weren't provided by a good lighting.

The design of specialized streets were planned to support special theme which indicated on material differences compared to the surrounding areas. The connectivity over the specialized street smoothly planned with hierarchy on the material and facilities differences [13]. The small block was injected in both specialized streets to give easy access, nevertheless the Insadong's street wasn't designed with a proper windbreaker in the street which results in multi-use access. In other hands, the passengers will get trouble walking on this area during windy seasons. The strict reinstatement about the specialized street impacts the traffic calming protection over pedestrian way, maintenance, and installation of public art. According to the evaluation of Nampodong, mix use access of pedestrians, cars and motorbikes in the specialized street gives low protection for passengers access. The installment of the median island also able to give wind breaker effect. The rest area facilities were provided even though the distance between each area was more than standard of $20 \mathrm{~m}$.

Street furniture's major problems were maps, hand railing, public amenities that only few on the specialized street. That conditions may impact on difficulties to get information on the site and difficulties on access for the disabled persons. In addition to this, Insadong has permanent and more memorable street furniture with simple and local character design rather than Nampo that use uniformity on street furniture.

The street utilities are almost similar to the street furniture section [14]. In a further evaluation, drainage control design on several spots at Insadong may give difficulty with open type and unsafe manhole design.

The signage section had been a vital part in the tourism industry of South Korea since this country using a different alphabet, but it may cover with international form / drawings of signage. Non visual signage such sound and touchable sign were not provided on both country's specialized streets may burden the disabled person to find the information on this site. Most of building information was designed well to give the first impression to the passengers with local art instalments and contrast adjusts the designs. In Nampodong, the map area was not perceptible enough to locate where we are. And the reduplication of building signage makes disorientation of the spot thus problem may solve with a portable map but not solve in environmental design point. The permanent public art installation gives landmark point on the area to locate the spot. In some area, dark spot was found on the pedestrian way that give visual and psychological barrier for the passengers.

The street materials on both specialized streets are well planned designs that give identity and non-slippery, non-glare, safe access to the passenger. Furthermore, the permanent ramp installment makes competition to the accessibility, but the improper tactile location makes some problems to the users especially for distance connection. Soft material such rubberized tile perform better for pedestrian access and signage but was not provided in urban streets and prefer to hard material like cobble stone, marble, and low grate concrete pavements which cause pedestrian fatigue faster than the soft materials. 


\section{Conclusion}

Based on analysis and comparisons of specialized streets which examined by the evaluation sheets, this study concluded with some points as follows : South Korea cases are good practices in universal design principles application, urgency of implementing the universal design based direction into local regulations so some problems can be solved; and change of urban development paradigm from partial based design into universal design based.

\section{References}

1. Islington Council, Islington Street book A boroughwide streetscape manual, Islington Council London (2005)

2. Otak Team, Scottsdale Road Streetscape Design Guidelines, city of Scottsdale: Arizona (2008)

3. Torbay council , Torbay Streetscape Design Guidelines, Torbay: United Kingdom (2004)

4. Putra, Budi A., Cultural Representation of Vernacular Housing in Jambi, Doctoral's thesis, Seoul National University, South Korea

5. Abu Dhabi Urban Planning Council, Abu Dhabi Utility Corridor Design Manual ver 1, Emirates of Abu Dhabi Urban Planning Council (2017)

6. Landcome, Street Project guideline, Landcome : New South Wales, Australia (2008)
7. Burton, Elizabeth; Lynee, Mitchell, Inclusive Urban Design: Street for Life, Elsevier Linacre House, Jordan Hill, Oxford (2006)

8. Guide Dogs on Behalf of Action for Blind People, Inclusive Streets: Design Principles for Blind and Partially Sighted People, Association of Visually Impaired Office Staff, Deafblind UK (2010) http://www.guidedogs.org.uk/media/1497778/Inclusi ve_Streets_Design_Principles_booklet_Guide_Dogs 2010.pdf)

9. Shehu, Vjosa, Universal Design Strategies On Developing Country, Case Study: Tirana, Master's thesis, Eposka University Tirana, Albania (2011)

10. Guimares, Marcello, An Assessment Of Understanding Universal Design Through Online Visual Resources and Role-Playing Simulation Exercises, North Carolina State University (2005)

11. Aslaksen, Universal design: Planning and Design for All, Cornel University (1997) accessed at http://digitalcommons.ilr.cornell.edu/gladnetcollect

12. Department of Transport, Manual for Street, Thomas Telford, London (2007)

13. Indrakusumo R.H., Bangun, Design Characteristics of Specialized Streets for Indonesia through Cases of South Korea Departement of Architectural Engineering, The Graduate School, Pukyong National University (2016)

14. Mehta, Vikas, Lively Streets: Exploring The Relationship Between Built Environment And Social Behavior, Doctoral's thesis, University of Maryland, College Park (2006) 